\title{
Strength and Microstructure of Reactive Powder Concrete Using Ternary Pozzolanic Materials
}

\author{
So, Hyoung-Seok ${ }^{1}$ Janchivdorj Khulgadai ${ }^{2}$ Yi, Je-Bang ${ }^{2}$ Jang, Hong-Seok ${ }^{2}$ So, Seung-Young ${ }^{2 *}$ \\ Department of Architectural Engineering, Seonam University, Kangchi-Dong, Namwon, 590-711, Korea ${ }^{1}$ \\ Department of Architectural Engineering, Chonbuk National University, Dukjin-Gu, Jeonju, 561-756, Korea ${ }^{2}$
}

\section{Abstract}

To consider the practicality and economic feasibility of developing reactive powder concrete (RPC), the strength and microstructure properties of RPC using ternary pozzolanic materials (silica fume, blast furnace slag, fly ash) were investigated in this study. Through the investigation, it was found that the compressive strength of RPC using ternary pozzolanic materials was increased significantly compared to that of the original RPC containing silica fume only. A considerable improvement in the flexural strength of RPC using ternary pozzolanic materials was found, and then the utilization of a structural member subjected to bending was expected. The X-ray diffractometer (XRD) analysis and Scanning Electronic Microscope (SEM) revealed that the microstructure of RPC was denser using the ternary pozzolanic materials than the original RPC.

Keywords : reactive powder concrete, ternary pozzolanic material, strength, microstructure

\section{Introduction}

\subsection{Research objective}

As the construction environment has been rapidly changing, building structures are becoming taller, larger, and more massive, and have a longer span. For this reason, the demands and requirements of high strength concrete and high performance concrete have been rising significantly. Of those concrete types, reactive powder concrete (RPC) has caught the attention of industry due to its physical properties, including not only high compressive strength greater than 170Mpa, and high ductility (high modulus of rupture greater than $25 \mathrm{MPa}$ and fracture energy as high as $30 \mathrm{~kJ} / \mathrm{m}^{2}$ ), but also its

Received : September 24, 2012

Revision received : November 28, 2012

Accepted : December 6, 2012

* Corresponding author : So, Seung-Young

[Tel: 82-63-270-4059, E-mail: archiso@jbnu.ac.kr]

(c)2013 The Korea Institute of Building Construction, All rights reserved. high flowability. RPC was developed by researchers at Bouygues laboratory in France in the early 1990s. The compressive strength of the RPC 800 made using high temperature, high pressure steam curing $\left(250 \sim 400^{\circ} \mathrm{C}\right)$ was reported to reach up to $800 \mathrm{MPa}$, which is as great as that of steel material[1].

Unlike ordinary concrete, fine quartz (less than $0.5 \mathrm{~mm}$ in size) is used instead of coarse aggregate, the bonding area of cement paste is greatly reduced, pores within the hardened cement are also greatly reduced through an appropriate mix of silica fume (reactive powder), an ultra fine particle, with cement, and an extremely low w/b ratio (less than $\mathrm{w} / \mathrm{c}=0.2$ ), and the compressive strength of the matrix is improved as a result. In addition, RPC is a cement composite that secures high flowability and high ductility by mixing superplasticizer and fiber. With superb mechanical properties, RPC are actively being studied in the 
center of Europe and the U.S. as one of the next-generation construction materials that can cope with the recent rapid changes in the construction environment. In particular, based on the initial data of RPC, many efforts have been made to improve RPC in diverse ways in relation with mechanical and physical properties and economic feasibility. Abouzar[2] performed research to develop a lightweight reactive powder concrete, and Halit et al.[3] reported that RPC with compressive strength as high as $250 \mathrm{MPa}$ could be obtained through steam curing and the combined use of diverse pozzolanic materials. In addition, a French private company developed 'DUCTAL' (product name) to achieve a balance between strength and deformation performance based on the initial data of RPC in 1990s, and this has been widely applied to structures. In Korea, however, even researchers and developers of building materials are not familiar with RPC. For this reason, not only are there few applications of $\mathrm{RPC}$, but there have been few studies on its use.

Meanwhile, in the original concept of RPC, the unit weight of cement is as high as 900 1000kg/ $\mathrm{m}^{3}$ due to the use of fine quartz (less than $0.5 \mathrm{~mm}$ in size) instead of coarse aggregate, and a large volume of relatively expensive silica fume is also used, which is not produced in Korea and thus must be imported. Since the density of RPC has a heavy weight at $2.5 \sim 3.0 \mathrm{~g} / \mathrm{cm}^{3}$. Thus, RPC needs to be modified for producing an economical material with high strength to weight ration. Recently, diverse studies should be implemented to develop RPC with more practicality and economic feasibility, but Korea has a long way to go before this is achieved.

Therefore, this study aims to provide fundamental data on developing RPC that is economically and practically feasible for Korea's situation by analyzing and assessing the basic physical properties and microstructures of RPC mixed with ternary pozzolanic materials (blast furnace slag, fly ash, silica fume). To do this, reduction in unit weight of cement and density within the performance range of the existing $\mathrm{RPC}$ was observed, and blast furnace slag and fly ash were used to determine whether silica fume could be replaced with those materials.

\subsection{Research method and scope}

Based on the existing basic mixing proportion of RPC, RPC was manufactured by adding single or mixed ternary pozzolanic materials such as silica fume, blast furnace slag and fly ash by mass of cement, up to 0 65\%. The basic physical and strength properties of the RPC were analyzed to determine whether RPC could be developed using ternary pozzolanic materials. Table 1 indicates the experimental factors and levels.

Table 1. Experimental factors and levels in this study

\begin{tabular}{|c|c|c|c|c|}
\hline \multicolumn{2}{|c|}{ Experimental factors } & \multicolumn{3}{|c|}{ Levels } \\
\hline \multirow{10}{*}{$\begin{array}{c}\text { Mixing } \\
\text { conditions }\end{array}$} & $\mathrm{W} / \mathrm{B} *(\%)$ & \multicolumn{3}{|c|}{15} \\
\hline & Table flow (mm) & \multicolumn{3}{|c|}{$125 \pm 5$} \\
\hline & \multirow{8}{*}{ 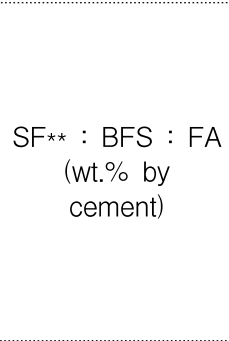 } & $\mathrm{SF} \star \star$ & BFS & FA \\
\hline & & 25 & 0 & 0 \\
\hline & & 65 & 0 & 0 \\
\hline & & 25 & 40 & 0 \\
\hline & & 25 & 0 & 40 \\
\hline & & 25 & 30 & 10 \\
\hline & & 25 & 10 & 30 \\
\hline & & 25 & 20 & 20 \\
\hline \multirow{2}{*}{$\begin{array}{l}\text { Curing } \\
\text { methods }\end{array}$} & Water & \multicolumn{3}{|c|}{$20 \pm 2^{\circ} \mathrm{C}$} \\
\hline & Steam & \multicolumn{3}{|c|}{$90^{\circ} \mathrm{C}, 72 \mathrm{hr}$} \\
\hline
\end{tabular}

*. W/B: Water/Binder ratio

**. SF: Silica Fume, BFS: Blast Furnace Slag, FA: Fly Ash

\section{Experiment}

\subsection{Materials}

1) Binder

As stipulated in KS L 5201, ordinary Portland 
cement (OPC) manufactured was used. As ternary pozzolanic materials, silica fume manufactured in Canada, blast furnace slag (BFS) from Gwangyang steel mill and fly ash from Boryeong in Korea were used, respectively. The physical and chemical properties of each of the ternary pozzolanic materials are indicated in Table 2.

\section{2) Aggregate}

Aggregate was used by mixing domestic quartz sand with a diameter of $0.3 \sim 0.5 \mathrm{~mm}$ and with a diameter of $0.15 \sim 0.3 \mathrm{~mm}$. The density of quartz was $2.65 \mathrm{~g} / \mathrm{cm}^{3}$ and its silica content $\left(\mathrm{SiO}_{2}\right)$ was $82 \%$ or higher.

3) Filling material

As filling material, quartz powder was used. The average diameter of the quartz powder was $45 \mu \mathrm{m}$, its density was $2.65 \mathrm{~g} / \mathrm{cm}^{3}$ and its silica content $\left(\mathrm{SiO}_{2}\right)$ was $92 \%$ or higher.

\section{4) Superplasticizer}

Polycarbonic superplasticizer made in Japanese was used. Its density was $1.05 \mathrm{~g} / \mathrm{cm}^{3}$, and $28 \%$ solid content brown liquid was used.

5) Steel fiber

Steel fiber for high elasticity of domestic Company S was used. The specification of the steel fiber was $0.5 \mathrm{~mm}$ in diameter, $30 \mathrm{~mm}$ in length, 7.8 of density, and $1,195 \mathrm{MPa}$ of tensile strength.

Table 2. Chemical and physical properties of binders

\begin{tabular}{|c|c|c|c|c|}
\hline Oxide (\%) & Cement & SF & BFS & FA \\
\hline $\mathrm{SiO}_{2}$ & 20.57 & 94 & 33.1 & 53.08 \\
\hline $\mathrm{Al}_{2} \mathrm{O}_{3}$ & 5.48 & 0.5 & 13.76 & 25.25 \\
\hline $\mathrm{Fe}_{2} \mathrm{O}_{3}$ & 3.18 & 2.0 & 0.85 & 12.84 \\
\hline $\mathrm{CaO}$ & 63.03 & 0.8 & 40.59 & 2.61 \\
\hline $\mathrm{MgO}$ & 3.41 & 0.9 & 7.22 & 1.37 \\
\hline $\mathrm{Na}_{2} \mathrm{O}+\mathrm{K}_{2} \mathrm{O}$ & 0.52 & 1.0 & - & 0.06 \\
\hline $\mathrm{SO}_{3}$ & 2.23 & 0.2 & 1.65 & 2.1 \\
\hline Blaine fineness $\left(\mathrm{cm}^{2} / \mathrm{g}\right)$ & 3,267 & 200,000 & 8,000 & 3,678 \\
\hline Specific gravity & 3.15 & 2.2 & 2.88 & 2.21 \\
\hline
\end{tabular}

\subsection{Manufacturing and curing of specimens}

1) Manufacturing of specimens

RPC using ternary pozzolanic materials was manufactured through preliminary tests based on the existing mix proportion of RPC. The mix proportions are presented in Table 3. SF25 type in Table 3 was the basic mix proportion of the existing RPC, where silica fume was mixed $25 \%$ by mass of cement $(\mathrm{SF} / \mathrm{C}=25 \%)$, which was made to perform a comparative analysis with RPC using ternary pozzolanic materials in terms of various physical properties and fine structures. The mix proportions of RPC with ternary pozzolanic materials were improved from the mix proportion of the existing RPC. The mix proportions of pozzolanic materials were set to $65 \%$, and quartz sand $0.15 \sim 0.3 \mathrm{~mm}$ in size and quartz powder with an average diameter of $45 \mu \mathrm{m}$ were used to obtain the closest packing and improve the packing of concrete matrix. At this time, the mix proportion of pozzolanic materials was increased to $65 \%$, and the volume of the cement was reduced greatly compared to the existing mix proportion (SF25).

Table 3. Mix proportions

\begin{tabular}{lcccccccc}
\hline \multicolumn{1}{c}{ Mix. } & SF25 & SF65 & B40 & F40 & B30F10 & B1OF30 & B20F20 \\
\hline Cement $\left(\mathrm{kg} / \mathrm{m}^{3}\right)$ & 950 & 725 & 767 & 740 & 766 & 766 & 759 \\
Silica fume $\left(\mathrm{kg} / \mathrm{m}^{3}\right)$ & 238 & 472 & 192 & 185 & 192 & 192 & 190 \\
Blast furnace slag $\left(\mathrm{kg} / \mathrm{m}^{3}\right)$ & - & - & 307 & - & 230 & 77 & 152 \\
Fly ash $\left(\mathrm{kg} / \mathrm{m}^{3}\right)$ & - & - & - & 296 & 77 & 230 & 152 \\
$0.3 \sim 0.5 \mathrm{~mm}$ Quartz & 996 & 508 & 537 & 518 & 536 & 536 & 531 \\
$\left(\mathrm{~kg} / \mathrm{m}^{3}\right)$ & & & & & & & \\
$0.15 \sim 0.3 \mathrm{~mm}$ Quartz & - & 145 & 153 & 148 & 153 & 153 & 152 \\
$\left(\mathrm{~kg} / \mathrm{m}^{3}\right)$ & & & & & & & \\
$0 \sim 45 \mu \mathrm{m}$ Quartz powder & - & 145 & 153 & 148 & 153 & 153 & 152 \\
$\left(\mathrm{~kg} / \mathrm{m}^{3}\right)$ & & & & & & & \\
Steel fiber $\left(\mathrm{kg} / \mathrm{m}^{3}\right)$ & 190 & 203 & 215 & 207 & 215 & 215 & 213 \\
Super-plasticizer $\left(\mathrm{kg} / \mathrm{m}^{3}\right)$ & 36 & 44 & 46 & 44 & 46 & 46 & 46 \\
Water $\left(\mathrm{kg} / \mathrm{m}^{3}\right)$ & 190 & 167 & 153 & 148 & 146 & 146 & 144 \\
Water $/$ cement ratio & 0.20 & 0.28 & 0.25 & 0.25 & 0.25 & 0.24 & 0.24 \\
Water $/$ binder ratio & 0.16 & 0.17 & 0.15 & 0.15 & 0.15 & 0.14 & 0.14 \\
Table flow $(\mathrm{mm})$ & 120 & 118 & 129 & 128 & 124 & 130 & 128 \\
\hline
\end{tabular}


To mix all the specimens, a steel mixer (10L) was used, and binder (cement, silica fume, blast furnace slag, fly ash) and quartz powder (45um in diameter) were dry-blended for 5 minutes, and then quartz was added to the mixed materials, and dry-blended for another 5 minutes. In the dry-blended mortar, mixing water, steel fiber and superplasticizer were added and then blended for another 5 minutes. It took 15 minutes in total to blend the specimens. The target slump flow was set at $125 \pm 5 \mathrm{~mm}$, and 3.0 3.6\% superplasticizer was added by mass of binder.

2) Curing method

For the RPC specimens manufactured for the test, water curing and steam curing were carried out at room temperature $\left(20^{\circ} \mathrm{C}\right)$ and at $90^{\circ} \mathrm{C}$, respectively. For the water curing at room temperature $\left(20^{\circ} \mathrm{C}\right)$, the specimens were first placed in molds and left in a constant temperature and humidity chamber $\left(20 \pm 2^{\circ} \mathrm{C}\right.$, RH $\left.60 \pm 5 \%\right)$ for 1 day (24hr), and then the molds were removed. The specimens were placed in a curing water tank $\left(20 \pm 2^{\circ} \mathrm{C}\right)$ before the test. For the steam curing at $90^{\circ} \mathrm{C}$, the specimens were first placed in molds and left in a constant temperature and humidity chamber for 1 day (24hr), and the molds were removed. The specimens were placed and left in a steam curing chamber at $90^{\circ} \mathrm{C}$ for 3 days (heating rate of $10^{\circ} \mathrm{C} / \mathrm{hr}$ ), and then placed in a constant temperature and humidity chamber for dry curing before the test.

\subsection{Test items and method}

1) Compressive and flexural strength

In terms of compressive and flexural strength, the strength developed at each age was measured for specimens with a dimension of 40x40x160mm in accordance with KS F2450 and F2408. At this time, the flexural strength was measured using the center point loading method.

2) Density and absorption

The density and absorption test was performed at 28 days with the RPC specimens (40x40x160mm) in compliance with KS F2518.

3) Microstructure analysis

To examine the microstructure of respective specimens by experimental factor, mercury intrusion porosimetry (MIP) was employed to measure the pore structure, and X-ray diffractometer (XRD) and Scanning Electronic Microscope (SEM, JSM-5900) were employed to analyze and observe hydrates. The pore structures of each specimen and the specimens for the XRD and SEM analysis were collected from the specimens $(40 \times 40 \times 160 \mathrm{~mm})$ based on curing method and age through crushing or pulverization, and then were processed through D-dry treatment after the emersion in acetone, and then measured. The pore structures were measured using MIP within the pore radius range of $003 \sim 10 \mu \mathrm{m}$. The maximum pressure applied was 46,793 psi (3,290kgf/ $\left.\mathrm{cm}^{2}\right)$, contact angle was $130^{\circ}$, and the surface tension of the mercury was $6.95 \times 10^{-5} \mathrm{psi}\left(0.489 \times 10^{-5} \mathrm{kgf} /\right.$ $\left.\mathrm{cm}^{2}\right)$. In addition, the scan speed of XRD was $4^{\circ} / \mathrm{min}$, and the range of the diffraction angle was $10 \sim 80^{\circ}$.

\section{Test results and examination}

\subsection{Properties of strength development of RPC with ternary pozzolanic materials}

Figure 1 shows the results of a comparison of the properties of the compressive strength of RPC using ternary pozzolanic materials with those of Plain (SF25). As shown in Figure 1, the compressive strength of the specimens (mixed with $\mathrm{SF}, \mathrm{BFs}$ and FA) was shown to be higher than that of Plain (SF25) with 25\% of SF only (SF/C) except 
for the specimen water cured at $20^{\circ} \mathrm{C}$ at 1 day, from which it was proven that the mix of ternary pozzolanic materials had an impact on improvements in strength. Notably, the compressive strength of B40 and B30F10 water cured at room temperature $\left(20^{\circ} \mathrm{C}\right)$ was higher than $100 \mathrm{MPa}$ at 3 days, and even reached around $150 \mathrm{MPa}$ at 28 days. The compressive strength of B40 and B30F10 steam cured $(72 \mathrm{hr})$ at $90^{\circ} \mathrm{Cwas}$ improved to $181 \mathrm{MPa}$ and 188MPa. However, the compressive strength of RPC with ternary pozzolanic materials was lower than that of SF25 and SF65 at 1 day. This is attributed to the mix proportion of pozzolanic materials was increased up to 65wt.\% while the volume of cement was relatively decreased, and the pozzolanic reaction of the materials was retarded, thus retarding the development of the strength of the specimens. In addition, the smaller fineness of $\mathrm{BFS}$ and FA than that of SF is believed to have had an influence. The characteristics of pozzolanic reaction in RPC with ternary pozzolanic materials can be confirmed from the analysis of hydrates by age (See Figure 9).

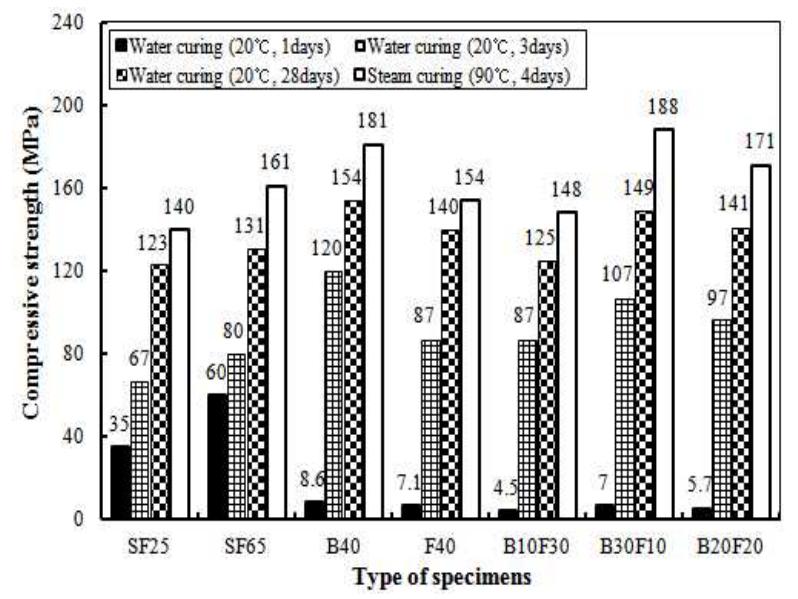

Figure 1. Influence of pozzolanic materials type and content, curing conditions on compressive strength

On the other hand, the compressive strength of RPC with ternary pozzolanic materials improved by about $10 \%$, up to $26 \%$, which is believed to be because the pozzolanic reaction of $\mathrm{SF}, \mathrm{BFS}$, and $\mathrm{FA}$ was activated and accelerated by non-hydrated silica $\left(\mathrm{SiO}_{2}\right)$ particles. The improvement in strength by steam curing at $90^{\circ} \mathrm{C}$ was evident in $\mathrm{B} 40$ and $\mathrm{B} 30 \mathrm{~F} 10$, in which a relatively large mix proportion of BFS was set.

Figure 2 shows the flexural strength of RPC specimens with ternary pozzolanic materials by curing method and age. As shown in Figure 2, the flexural strength of RPC with ternary pozzolanic materials was noticeably higher than SF25 or SF65 with silica fume only, regardless of the curing method. In particular, flexural strength was most improved in B20F10. When steam cured at $90^{\circ} \mathrm{C}$, the flexural strength was increased by $68 \%$ compared with that of SF25 (21 MPa). In addition, as shown in Figure 2, the flexural strength of RPC with ternary pozzolanic materials was improved more overall than the compressive strength, except for the specimens that were water cured at $20^{\circ} \mathrm{Cat}$ 1 day.

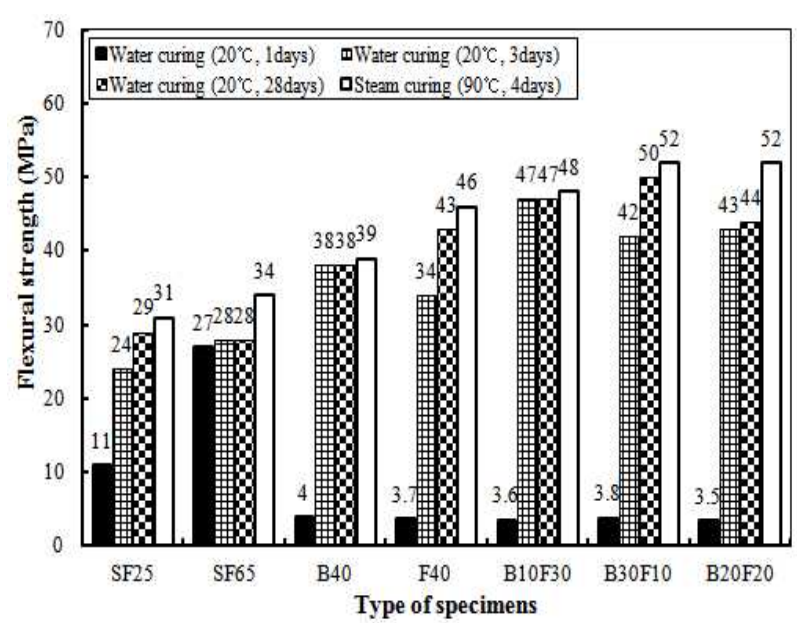

Figure 2. Influence of pozzolanic materials type and content, curing conditions on flexural strength

Thus, to perform a detailed analysis of the improvement in flexural strength, the ratio of flexural strength over the compressive strength 
$\left(\mathrm{F}_{\mathrm{b}} / \mathrm{F}_{\mathrm{c}}\right)$ was examined, and the results were illustrated in Figure 3. As shown in Figure 3, the ratio of flexural strength over compressive strength of RPC with ternary pozzolanic materials was higher than that of SF25 or SF65 with silica fume only. In B10F20, it was improved to about 0.38 (water cured at $20^{\circ} \mathrm{C}$ ). And with the exception of $\mathrm{B} 40$, the $\mathrm{F}_{\mathrm{b}} / \mathrm{F}_{\mathrm{c}}$ factor of $\mathrm{RPC}$ with ternary pozzolanic materials was shown to be higher than 0.3, from which it was confirmed that the mix of pozzolanic materials had an impact on improving the strength of RPC.

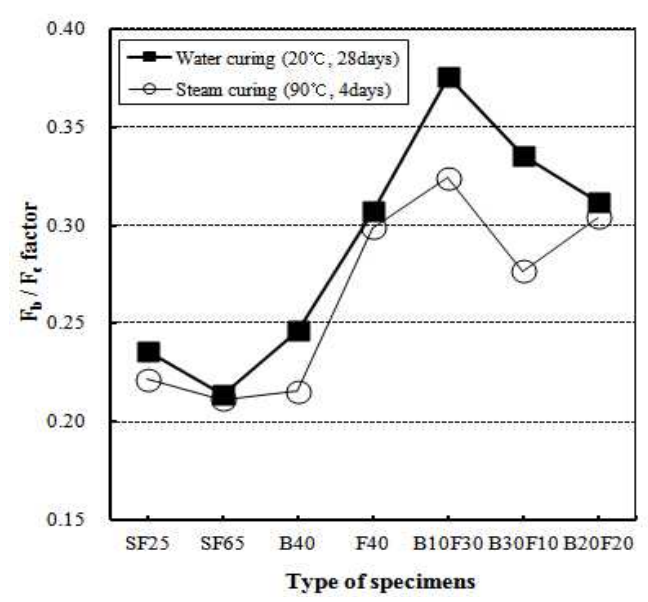

Figure 3. Fb/Fc factor of RPC

On the other hand, Figure 4 shows the splitting tensile strength of RPC with ternary pozzolanic materials by curing method and age. As shown in Figure 4, the splitting tensile strength of RPC with ternary pozzolanic materials was equivalent in the specimens water cured at $20^{\circ} \mathrm{Cand}$ SF25 and SF65 with silica fume only, but was improved by about $19 \sim 31 \%$ through steam curing at $90^{\circ} \mathrm{C}$ (except for B40).

In particular, the splitting tensile strength was measured at $21 \mathrm{MPa}$ and $20 \mathrm{MPa}$ in $\mathrm{F} 40$ and B10F20, where a large mix proportion of FA was set, and had a good impact on improving the splitting tensile strength.

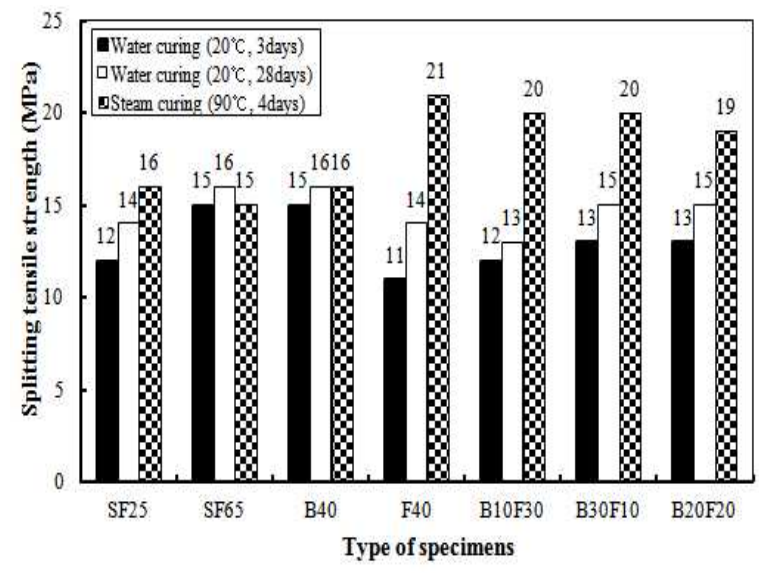

Figure 4. Influence of pozzolanic materials type and content, curing condition on splitting tensile strength

The results above show that having an appropriate mix of ternary pozzolanic materials could be an effective method to greatly improve the strength of RPC. In particular, the mix of ternary pozzolanic materials was proven to be an excellent means of improving the flexural strength of RPC, and ways to utilize the ternary pozzolanic materials as a flexural member are actively sought. Furthermore, the existing RPC are reported to have problems, including drastic hydration, high hydration heat, and dry shrinkage caused by high unit volume of cement $\left(950 \mathrm{~kg} / \mathrm{m}^{3}\right)$ and a low $\mathrm{w} / \mathrm{b}$ ratio; however, the unit volume of cement was greatly reduced in RPC with ternary pozzolanic materials (while for binders, unit volume of pozzolanic materials was relatively increased), and unlike hydration reaction in cement, the pozzolanic reaction noticeably contributes to a reduction in hydration heat and dry shrinkage. In addition, a great volume of the pozzolanic reactants generated (C-S-H or $\mathrm{C}^{-} \mathrm{A}-\mathrm{S}-\mathrm{H}$ gel) is expected not only to improve strength but also microstructure (compact improvement) in terms of durability. (see Figure 8) 


\subsection{Density and absorption of RPC with ternary pozzolanic materials}

Figure 5 illustrates the density and absorption of RPC specimens with ternary pozzolanic materials and Plain (SF25). As shown in Figure 5, the density of SF25 and SF65 to which silica fume was added only was shown at around $2.4 \mathrm{~g} / \mathrm{cm}^{3}$, while the density of RPC with ternary pozzolanic materials was shown to be less than $2.4 \mathrm{~g} / \mathrm{cm}^{3}$, except for B40. Of the specimens, the density of F40 and B10F30, in which a large mix proportion of FA was set, were shown as $2.24 \mathrm{~g} / \mathrm{cm}^{3}$ and as $2.22 \mathrm{~g} / \mathrm{cm}^{3}$, respectively. However, the absorption of RPC specimens had an inverse relationship to density. B10F30 was lowest in density, but at $2.75 \%$ in absorption, was higher than SF25. Overall density of RPC with ternary pozzolanic materials was lower than that of SF25, except for B10F30. Of them, B20F20 was the lowest, at 2.33\%. In terms of the utilization of RPC, high strength and low density are important factors, and the density properties of RPC with ternary pozzolanic materials are expected to be advantageous in terms of its practicability and utilization.

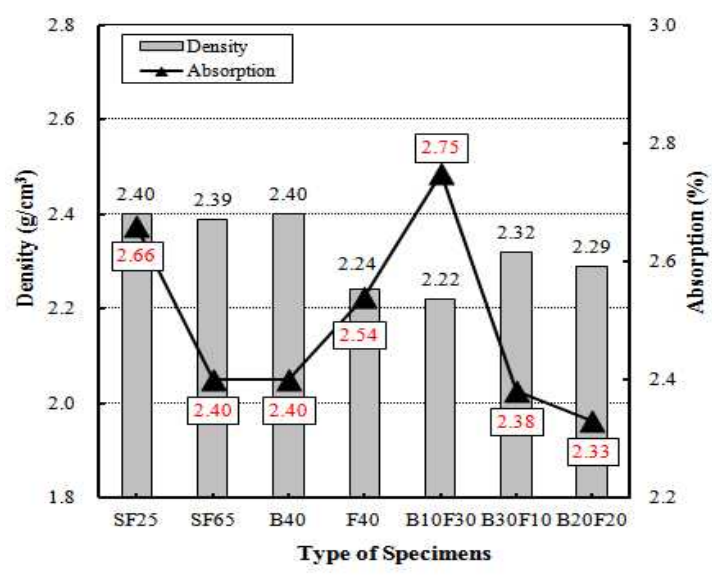

Figure 5. Density and absorption of RPC using ternary pozolanic materials $\left(20^{\circ} \mathrm{C}\right.$ water curing, 28days)

\subsection{Microstructure of RPC with ternary pozzolanic materials}

The pore structure of B40 by age, selected for pore structure analysis, is shown in Figure 6. As shown in Figure 6, porosity of B40 was 19.63\% at 1 day, but significantly decreased to $11.88 \%$ at 3 days. After 3 days there were no substantial changes in porosity, with porosity at 7 days and at 28 days $11.92 \%$ and $10.98 \%$, respectively. This indicates that hydration of cement and pozzolanic reaction were greatly activated in RPC with ternary pozzolanic materials at initial age (3 days) by unit volume of cement, high grain size of silica fume, and a low w/b ratio. This can also be found in the XRD analysis results (See Figure 9). And as shown in Figure 6 b) pore size distribution, the porosity was decreased with the passage of time, while it was found the volume of pores with a small diameter increased. The pore size that accounted for the highest volume was $0.05 \mu \mathrm{m}$ $(50 \mathrm{~nm})$ at 1 day, $0.027 \mu \mathrm{m}(27 \mathrm{~nm})$ at 3 days, 0.016 $\mu \mathrm{m}(16 \mathrm{~nm})$ at 7 days, and $0.028 \mu \mathrm{m}(28 \mathrm{~nm})$ at 28 days, gradually decreasing with the passage of time.

On the other hand, Figure 7 shows the comparison of pore structures between B40 water cured at $20^{\circ} \mathrm{C}$ and $\mathrm{B} 40$ steam cured at $90^{\circ} \mathrm{C}$ (porosity and pore size distribution). As shown in Figure 7, the porosity of RPC steam cured at $90^{\circ} \mathrm{C}$ for 72 hours was shown to be slightly lower than that of RPC water cured at $20^{\circ} \mathrm{C}$, while the pore size distribution was significantly different between the two RPCs. That is, the volume of the pores with a size of $0.01 \sim 0.028 \mu \mathrm{m}$ was observed to be significantly high in the RPC specimen that was water cured $\left(20^{\circ} \mathrm{C}\right)$, while low porosity was observed in the RPC specimen that was steam cured $\left(90^{\circ} \mathrm{C}\right)$ since cement hydration and pozzolanic reaction were greatly activated at an initial age, 
and the porosity in the matrix was decreased, particularly pores with a size of $0.01 \mu \mathrm{m}$ or bigger. This property can also be found in Figure 8, which shows the pore structure of RPC with ternary pozzolanic materials steam cured at $90^{\circ} \mathrm{C}$. The pores with a size of $0.01 \mu \mathrm{m}$ or smaller were increased, while the pores with a size of $0.01 \mu \mathrm{m}$ or bigger were decreased. The porosity of RPC with ternary pozzolanic materials was lower overall than that of SF25, from which the mix of pozzolanic materials was found to improve the pore structure of RPC. In addition, the porosity of B30F10 and B20F20 was shown to be lower than other specimens, from which the mix of SF, BFS and FA is found to be effective for improving the pore structure. As shown above, the pore structure of RPC with ternary pozzolanic materials corresponded to the other test results, which can be utilized as fundamental data to explain the density and absorption and strength development of each specimen.

On the other hand, Figure 9 illustrates XRD analysis results of hydrates of B40 specimens by age. As shown in Figure 9 a), b) and c), as the cement was hydrated at 1 day, hydrates including ettringite $(\mathrm{E})$ and calcium hydroxide $(\mathrm{CH})$ were formed, and as the pozzolanic reaction between $\mathrm{SiO}^{2}$ and $\mathrm{Al}_{2} \mathrm{O}_{3}$ and calcium hydroxide was progressed, the volume of calcium hydroxide decreased. Instead, calcium silicate hydrate (C; $\mathrm{C}-\mathrm{S}-\mathrm{H})$ or calcium aluminum silicate hydrate (CA; $\mathrm{C}-\mathrm{A}-\mathrm{S}-\mathrm{H})$ gel were generated. This result gives a good explanation for the pore structure and strength development of B40 by age, as shown in Figure 6. As illustrated in Figure 9 d), as hydration of cement and pozzolanic reaction were greatly activated at an initial age, the calcium hydroxide decreased noticably, while the volume of $\mathrm{C}-\mathrm{S}-\mathrm{H}(\mathrm{C})$ and $\mathrm{C}-\mathrm{A}-\mathrm{S}-\mathrm{H}(\mathrm{CA})$ gel increased.

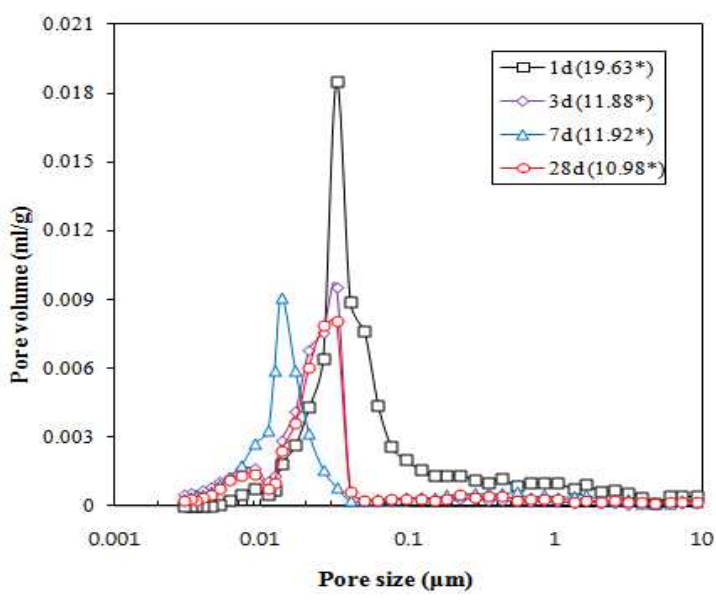

Figure 6. Pore size distribution with curing period of RPC (B40, $20^{\circ} \mathrm{C}$ water curing), Note; $*=$ total pore volume

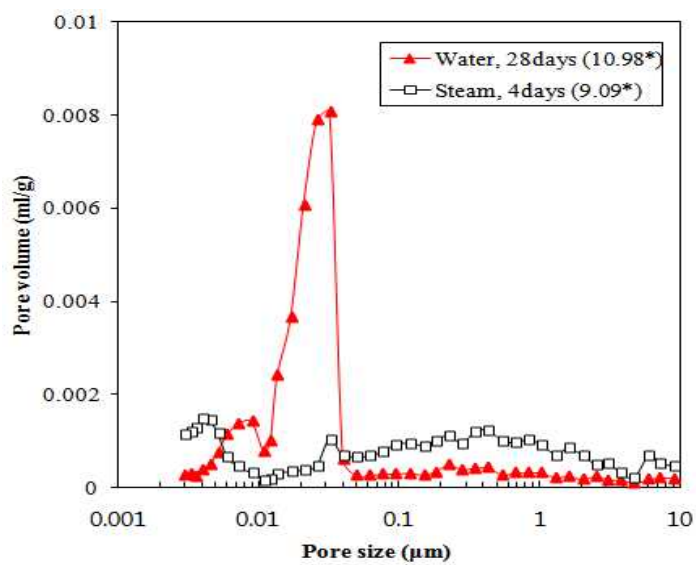

Figure 7. Influence of curing method on pore structure of RPC (B40) Note; *=total pore volume

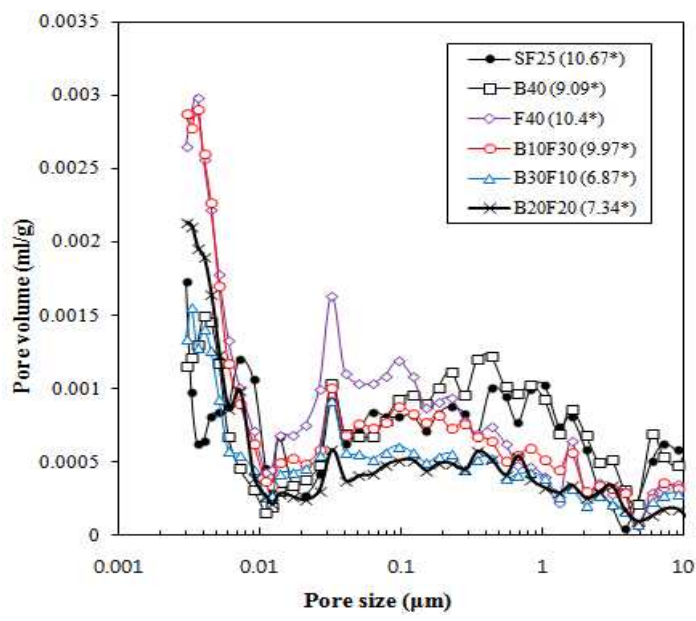

Figure 8. Pore size distribution of RPC $\left(90^{\circ} \mathrm{C}\right.$ steam curing, 4days), Note; *total pore volume 

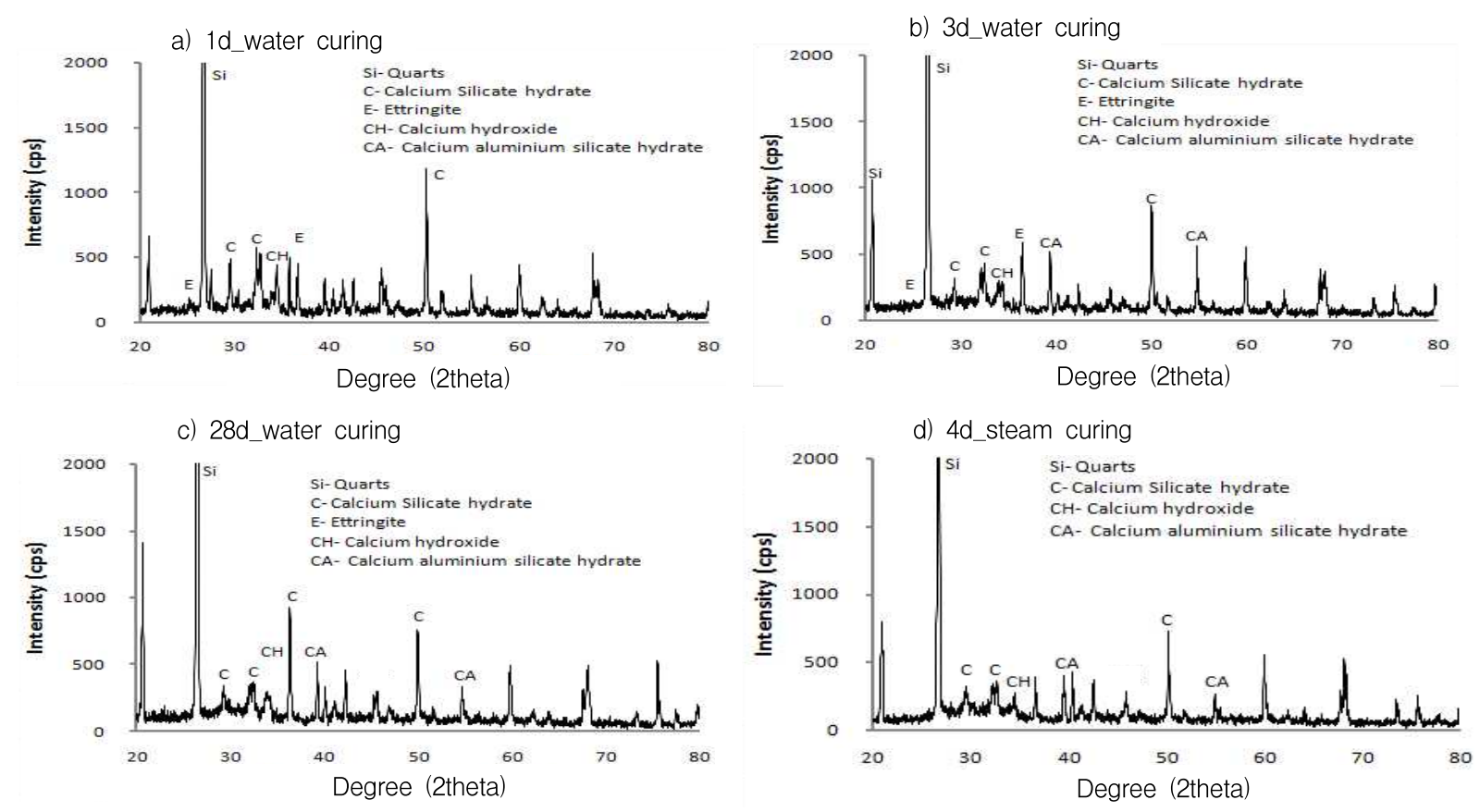

Figure 9. XRD results of $20^{\circ} \mathrm{C}$ water and $90^{\circ} \mathrm{C}$ steam cured $\mathrm{B} 40$ mixture

Figure 10 shows the SEM analysis of hydrates in B10F30 steam cured at $90^{\circ} \mathrm{C}$, and as shown in Figure 10, fiber shaped $\mathrm{C}-\mathrm{S}-\mathrm{H}$ and porous hydrates were found in the RPC with FA, which were not found in the other specimens. This provides a good explanation for why the porosity of F40 and B10F30 with FA was larger than that of the other specimens shown in Figure 8.
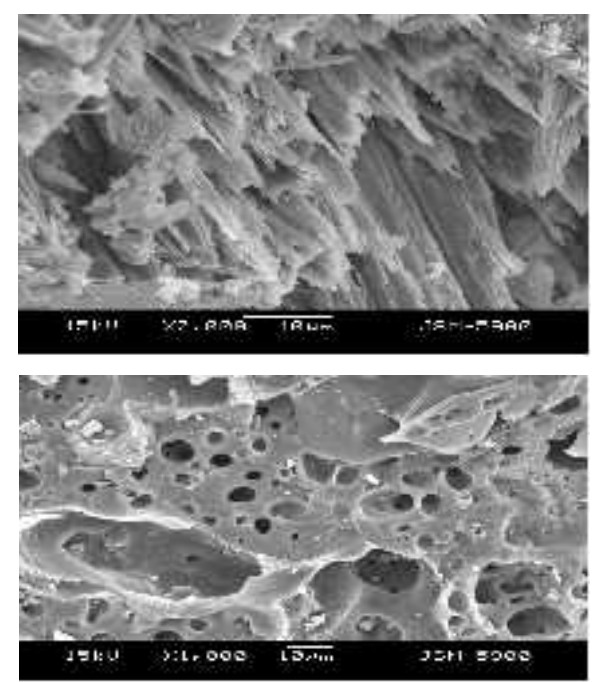

Figure 10. SEM images of $90^{\circ} \mathrm{C}$ steam cured B1OFA30 mixture

\section{Conclusion}

1) Compared with the existing RPC made with basic mix proportion (unit volume of cement of $950 \mathrm{~kg} / \mathrm{m}^{3}$ ), the unit volume of cement of RPC with ternary pozzolanic materials (mixed up to $65 \%$ by mass of cement) was greatly reduced at $750 \mathrm{~kg} / \mathrm{m}^{3}$, while the compressive, flexural and splitting tensile strength was greatly increased, by 34\% (B30F10), 68\% (B20F20), and $31 \%$ (F40). It is indicated that the mix of BFS, FA and SF that has a bigger grain size than cement improved the packing of the matrix, which is substantiated by the analysis result of the pore structure of each specimen.

2) In particular, the microstructure and strength were greatly improved in B30F10 and B20F20, where the mix proportion of SF, BFS and FA was set similarly.

3) The flexural strength was greatly improved, to $52 \mathrm{MPa}$, in $\mathrm{B} 30 \mathrm{~F} 10$ and $\mathrm{B} 20 \mathrm{~F} 20$ steam 
cured at $90^{\circ} \mathrm{C}$ for 72 hours, which is $68 \%$ higher compared with $31 \mathrm{MPa}$ of Plain, and the $F_{b} / F_{c}$ factor was 0.38 . Thus, RPC with ternary pozzolanic materials is actively sought to be utilized as a flexural member.

4) The strength properties of RPC with ternary pozzolanic materials were observed to be highest at $188 \mathrm{MPa}$ of compressive strength, $52 \mathrm{MPa}$ of flexural strength, and $20 \mathrm{MPa}$ of splitting tensile strength in B30F10 steam cured at $90^{\circ} \mathrm{C}$ for 72 hours.

5) On the other hand, the density of B30F10 and B20F20 (water cured at $20^{\circ} \mathrm{C}$, at 38 days) was observed at $2.32 \mathrm{~g} / \mathrm{cm}^{3}$ and $2.29 \mathrm{~g} / \mathrm{cm}^{3}$ lower than that of Plain, while the absorption of $\mathrm{B} 30 \mathrm{~F} 10$ and B20F20 (water cured at $20^{\circ} \mathrm{C}$, at 38 days) was improved by $2.38 \%$ and $2.33 \%$ compared with that of Plain.

6) In particular, Plain has the problems of cracking caused by high hydration heat and dry shrinkage due to its high volume of cement (950 $\mathrm{kg} / \mathrm{m}^{3}$ ), as well as an extremely low $\mathrm{w} / \mathrm{b}$ ratio. However, the unit volume of cement of RPC with ternary pozzolanic materials was noticeably reduced (while the volume of pozzolanic materials was relatively increased), and unlike hydration, pozzolanic reaction contributed not only to a great reduction in hydration heat and dry shrinkage but also to improved strength through the pozzolanic reactants $\left(\mathrm{C}^{-} \mathrm{S}-\mathrm{H}\right.$ and $\mathrm{C}^{-} \mathrm{A}-\mathrm{S}-\mathrm{H}$ gel), and improvements in durability can be expected as a result.

\section{Acknowledgement}

This research was supported by a grant (2012-R1A1A200-8719) from the National Research Foundation of Korea (NRF) grant funded by the Korea government (MEST)

\section{References}

1. Richard P, Cheyrezy MH. Reactive powder concrete with high ductility and 200-800 MPa compressive strength, ACI Spring Convention, San Francisco, SP.144-24, 1994;507-17.

2. Abouzar S. Development of a light weight reactive powder concrete. Journal of Advanced Concrete Technology. 2004 October;2(3):409-17.

3. Halit Yi, Mert YY, Serdar A, Anil S. Karabulut. Mechanical properties of reactive powder concrete containing high volumes of ground granulated blast furnace slag. Construction and Building Materials. 2009 March;23(3):1223-31.

4. Orange G, Acker P, Vernet C. A new generation of UHP concrete(DUCTAL damage resistance and micro-mechanical analysis). In: Reinhardt H.W. and Naaman A.E. High Performance Fiber Reinforced Cement Composites(HPFRCC3); 3rd International RILEM Workshop; 1999; Mainz, Germany. France: RILEM; 1999. p. 101-11.

5. Richard P, Cheyrezy MH. Composition of reactive powder concretes. Cement and Concrete Research. 1995;25(7):1501-11.

6. Cheyrezy M, Maret V, Frouin L. Microstructural analysis of RPC(Reactive powder concrete). Cement and Concrete Research. 1995;25(7):1491-500.

7. Mansoutre S, Lequeux N. Quantitative phase analysis of portland cements from reactive powder concrete by X-ray powder diffraction. Advanced in Cement Research. 1996;8(32):175-82.

8. Bae SH, The state of the art of ultra-high strength and high-toughness concrete using reactive powder concrete (RPC). Magazine of the Korea Concrete Institute. 2003; 15(3):129-33.

9. So SY, Yi JB, Khulgadai J, So HS. Strength development and micro-structure of reactive powder concrete containing meta-kaolin. Journal of the Architectural Institute of Korea, Structure \& Construction. 2011 December;27(12):147-54.

10. So HS, So SY. An experimental study on the strength development of ultra-high strength steel fiber reinforced cementious composites. Journal of the Architectural Institute of Korea, Structure \& Construction. 2009 July;25(7):63-70.

11. Lee BS, Kim SD, Jun MH, Park SS, Park SH, Jung SJ. Physical properties of $50 \mathrm{MPa}$ and $80 \mathrm{MPa}$ ternary high strength concrete before and after concrete pumping. Journal of the Korea Institute of Building Construction. 2012 August;12(4):451-9. 